\title{
Protein pannexin I and the sleep-wake cycle in model mice
}

\section{Introduction}

Recently a $17 y$ ears old female patient has been described carrying out a homozygous point mutation in the pannexin1 (Panxl) gene (an exchange of guanine to adenine at the position 650) which leads to the substitution of Arg for His at the position 217 in the expressed protein. This patient demonstrates multisystem dysfunction including intellectual disability, sensorineural hearing loss, skeletal defects, and primary ovarian failure. ${ }^{1}$ It was proposed that the primary origin of this global pathology is a structural change of the Panx1 protein discovered in 2000 by a Russian group. ${ }^{2}$ The ability to form ATP permeable membrane hemi-channels is regarded as one of the main functions of this protein. ATP molecules can exit the cell cytoplasm and enter the interstitial space through these hemi-channels and take part in the paracrine regulation. ${ }^{3}$ Extracellular ATP, in its turn, is the source of adenosine, the main known regulator of the sleep-wake cycle. ${ }^{4}$ Thus, we proposed that the Panxl gene mutation could also play an important role in sleep-wake disorders. ${ }^{5}$ Our experiments in Pan $^{-/}$mice demonstrated a significant increase in motor activity and wake percentage and correspondent decrease in slow wave (NREM) sleep especially expressed during the dark (active) period as compared to WT animals. ${ }^{6}$

It is well known that above its influence upon sleep-wake cycle, adenosine can significantly decrease body temperature. ${ }^{4,7}$ Thus we have proposed thermoregulatory and circadian body temperature disorders in $P_{\text {anx }}{ }^{-/}$mice. To check up the hypothesis, $8 \mathrm{WT}$ (C57Bl/6j) and 8 $P_{\text {an }}{ }^{-/}$mice under general anesthesia were implanted with miniature intraperitoneal autonomic temperature and movement probes. (The experimental protocol was approved by the ethic committee of the Severtsov Institute). Animals were placed to individual plastic boxes with 12/12 LD cycle and free access to water and food except for the series with torpor where availability to food was limited. Three ambient temperatures were used: (1) room temperature $\left(23 \pm 1^{\circ} \mathrm{C}\right)$; (2)

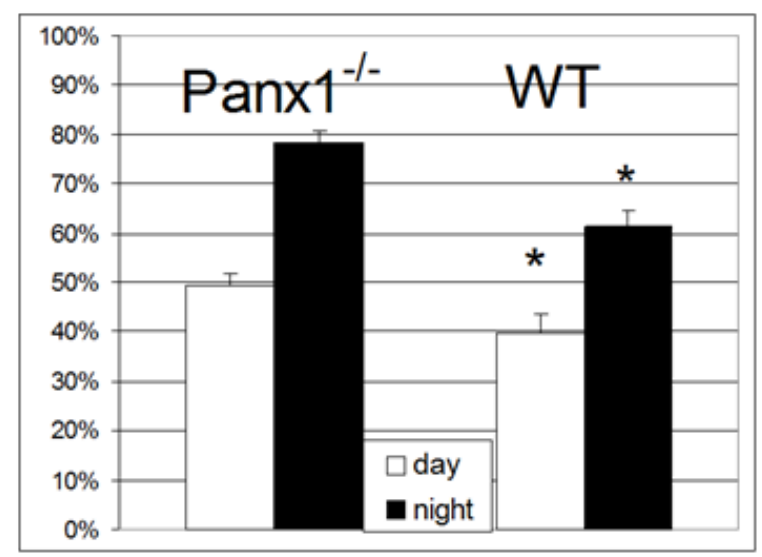

Volume 8 Issue 6 - 2018

\author{
Vladimir M Kovalzon, ${ }^{1,2}$ YuriV Panchin ${ }^{1,3}$ \\ 'Kharkevich Institute Information Transmission, Russian \\ Academy of Sciences, Moscow, Russia \\ ${ }^{2}$ Severtsov Institute Ecology/Evolution, Russian Academy of \\ Sciences, Moscow, Russia \\ ${ }^{3}$ Belozersky Institute Physical-Chemical Biology, Lomonosov \\ Moscow State University, Moscow, Russia
}

\begin{abstract}
Correspondence: Vladimir M Kovalzon, Severtsov Institute Ecology/Evolution, Russian Academy Sciences, 33, Leninsky Prospect, I I907I Moscow, Russia, Tel +7495954 I I I ,
\end{abstract} Email kovalzan@sevin.ru

Received: September 09, 2018 | Published: November 02, 2018

termoneutral zone for mice $\left(29 \pm 1^{\circ} \mathrm{C}\right)$; (3) low temperature when mice sometimes spontaneously fall into torpor $\left(11 \pm 1^{\circ} \mathrm{C}\right)$.

\section{Results}

The results confirmed our pervious data on higher behavioral moving activity of Panx ${ }^{-/}$mice as compared to the WT animals. This effect was especially pronounced during the dark period in the chamber (Figure 1). Circadian rhythm of body temperature in Panx $x^{--}$mice was normal and did not differ from WT controls. Other results were controversial. The experiments performed after the summer solstice revealed a decreased level of the basal body temperature and decreased response to pyrogene interleukine $1 \beta$ intraperitoneal administration $(10 \mu \mathrm{g} / \mathrm{kg})$ as well as an increased tendency to spontaneous falling into torpor within the room temperature in Panx $x^{--}$vs. WT mice. However the study performed after the winter solstice failed to demonstrate any changes between the Panx ${ }^{-/}$and WT groups.

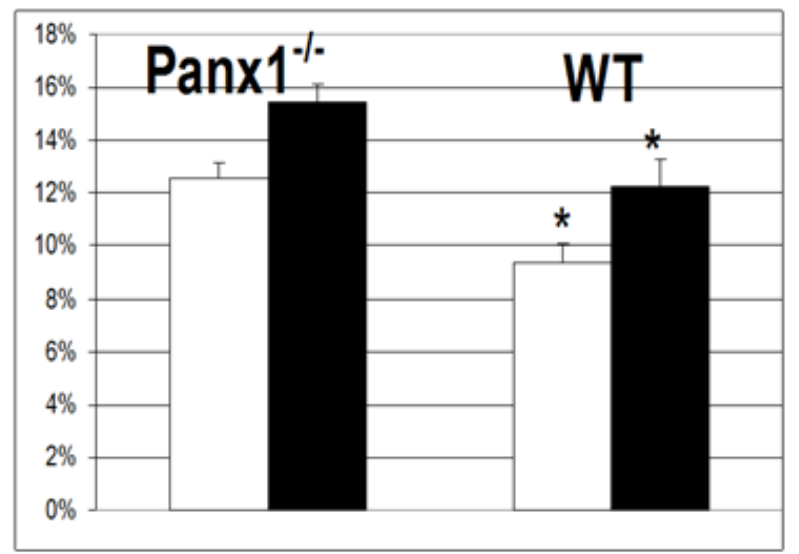

Figure I Movement activity in Panx ${ }^{-}$and WT mice. Left, total duration of the active periods during the day (light columns) and the night (black columns). Ordinate axis - time percentage $(100 \%=12 \mathrm{hrs})$. Right, movement intensity during the same periods in reference units (ordinate axis; I00\%=maximal possible deviation of the accelerometer). Data are presented in $\mathrm{M} \pm \mathrm{SEM}$. *indicate significant difference from the correspondent $P a n x^{-/}$data $(\mathrm{N}=8 / 8, \mathrm{P}=0.05, \mathrm{U}$-test). 


\section{Conclusion}

As we propose, increase in wake activity of $\operatorname{Panx}^{-/-}$mice is related to inefficient cerebral adenosine level as compared to the WT controls, which in its turn reflects the disorder of the supply of its source, the ATP, from the astrocytes to intercellular fluid due to the loss of Panx 1 membrane hemi-channels. Regarding body temperature, its regulation in mice needs to be more studied despite the great progress in this topic during the last years. ${ }^{7}$ Generally, the role of the Panxl gene in mice ultradian rest-activity rhythm was confirmed though the same in the temperature control still remains uncertain.

Nevertheless, both clinical and experimental data are in favor of the important role of Panx1 in the regulation of various physiological functions including the sleep-wake cycle.

\section{Acknowledgements}

Supported by the Russian Science Foundation, №17-15-01433.

\section{Conflict of interest}

Author declares that there is no conflict of interest.

\section{References}

1. Shao Q, Lindstrom K, Shi R, et al. A Germline Variant in the PANX1 Gene Has Reduced Channel Function and Is Associated With Multisystem Dysfunction. The Journal of Biological Chemistry. 2016;291(24):1243212443.

2. Panchin Y, Kelmanson I, Matz M, et al. A Ubiquitous Family of Putative Gap Junction Molecules. Curr Biol. 2000;10(13):R473-R474.

3. Esseltine JL, Laird DW. Next-Generation Connexin and Pannexin Cell Biology. Trends Cell Biol. 2016;26(12):944-955.

4. Holst SC, Landolt HP. Sleep Homeostasis, Metabolism, and Adenosine. Curr Sleep Medicine Rep. 2015;1(1):27-37.

5. Shestopalov VI, Panchin Y, Tarasova OS, et al. Pannexins Are Potential New Players in the Regulation of Cerebral Homeostasis during SleepWake Cycle. Front Cell Neurosci. 2017;11:210.

6. Kovalzon VM, Moiseenko LS, Ambaryan AV, et al. Sleep-Wakefulness Cycle and Behavior in Pannexin1 Knockout Mice. Behav Brain Res. 2017;318:24-27.

7. Silvani A, Cerri M, Zoccoli G, et al. Is Adenosine Action Common Ground for NREM Sleep, Torpor, and Other Hypometabolic States? Physiology. 2018;33(3):182-196. 